\title{
Synthesis of Cyclic Azo- and Hydrazo-Enaminones
}

\section{Monique Ferreira Marques* and Silvio Cunha}

\begin{abstract}
Universidade Federal da Bahia, Instituto de Química, Campus de Ondina, 40.170-290, Salvador - BA, Brasil INCT de Energia e Ambiente, Universidade Federal da Bahia, Campus de Ondina, Salvador - BA, 40170-290 *nique2405@yahoo.com.br
\end{abstract}

Keywords: enaminones, diazotation

\section{INTRODUCTION}

Enaminones are precious synthetic intermediates in carbo and heterocycles synthesis, once they can be easily obtained and are densily functionalized with many reactive centers, which provides their ambiphilic and ambident behavior. ${ }^{1}$ Azo-enaminones are obtained through the incorporation of the azo group in the $\mathrm{N}-\mathrm{C}=\mathrm{C}-\mathrm{C}=\mathrm{O}$ conjugated system. ${ }^{2}$ The azo group plays an important role in the eletrooptics properties $^{3}$ of these systems enhancing the structure planarity via an intramolecular hydrogen bonding and through its azo/hydrazo equilibrium. The planar conjugated $\pi$ systems are necessary to a maximum push-pull conjugation and have important applications in second order nonlinear optical devices. Given the enaminones' synthetic potential, our group decided to study these substances, developing new azo-enaminones.

\section{RESULTS AND DISCUSSION}

To the incorporation of the azo moiety into the enaminone structure, the coupling of cyclic enaminones with diazonium salts is the current approach. Thus, all the reactions were carried out at $0^{\circ} \mathrm{C}$, using dichloromethane as solvent and sodium acetate as base. The products obtained were recristalized from dichloromethane and hexane, and characterized by ${ }^{1} \mathrm{H}$ and ${ }^{13} \mathrm{C}$ NMR.

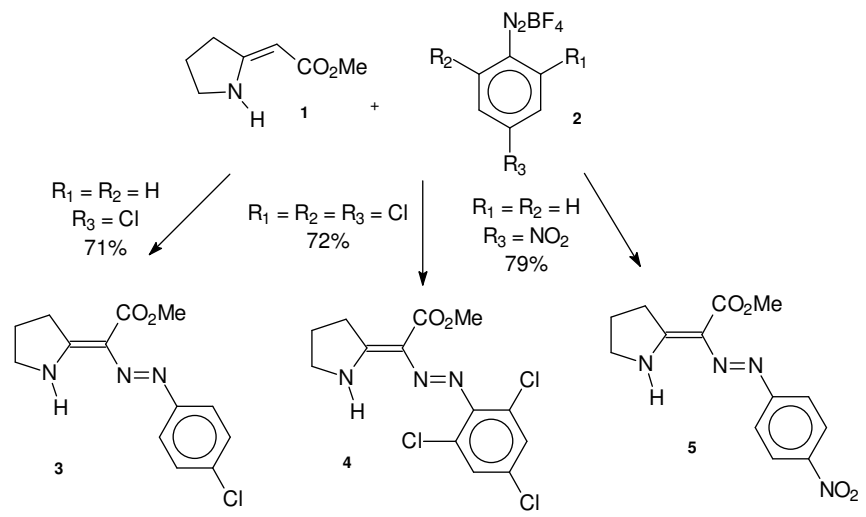

Scheme 1: Azo products
The five membered ring enaminone 1 was reacted with three diazonium salts, leading to the products in the azo form, as shown in Scheme 1. No peaks above 10ppm were observed in the ${ }^{1} \mathrm{H}$ NMR, indicating that the conformation of these products might be $Z$, which was corroborated by previously studies of $X$ ray diffraction.

When five membered ring enaminone $\mathbf{6}$, bearing exocyclic nitrogen, was reacted with diazonium salts, the observed products were in the hydrazo form, as shown in Scheme 2.

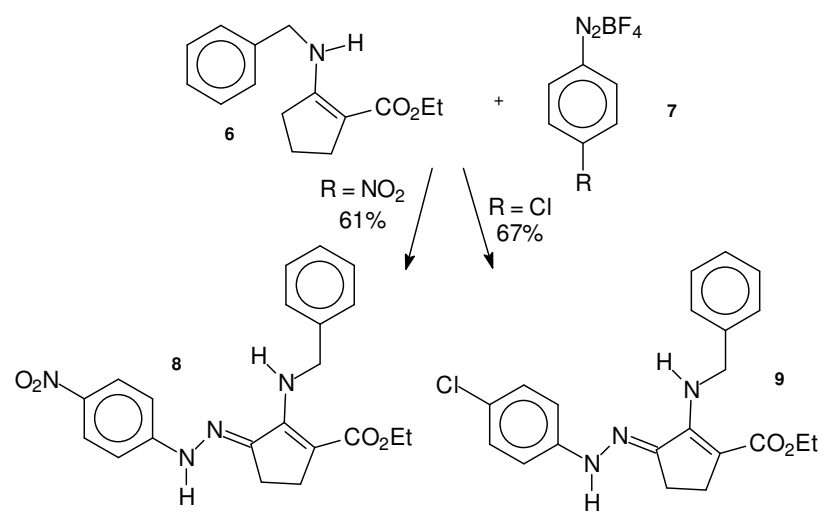

Scheme 2: Hydrazo products

The mechanism for the formation of compounds 8 and $\mathbf{9}$ is under $a b$ initio theoretical investigation.

\section{CONCLUSION}

Cyclic enaminones can react in more than one pattern with different diazonium salts. A more extensive work along these lines is in progress in our laboratory, once it is important to understand the behavior of polysubstituted cyclic enaminones in these reactions.

\section{ACKNOWLEDGEMENTS}

To CNPq, FAPESB and CAPES for the financial support.

\section{REFERENCES}

Chemla, D.S.; Zyss, J. Nonlinear Optical Properties of Organic Molecules and Crystals; Academic Press: New York, 1987, Vols. I e II.

${ }^{2}$ Lue, P.; Greenhill, J. V., Advances in Heterocyclic Chemistry; Katritzky, A. R., ed.; Academic Press: New York, 1997; Vol 67, pp 207-343.

${ }^{3}$ Kuckländer, V., The Chemistry of Enamines; Rappoport, Z., ed.; John Wiley \& Sons: New York, 1994; Part 1, pp 525-639. 